\title{
Effectiveness of Cognitive Therapy and Mindfulness Tools in Reducing Depression and Anxiety: A Mixed Method Study
}

\author{
Valerie L. Alexander*, B. Charles Tatum \\ Department of Psychology, National University, San Diego, USA \\ Email: valexand@nu.edu
}

Received 27 August 2014; revised 23 September 2014; accepted 9 October 2014

Copyright (C) 2014 by authors and Scientific Research Publishing Inc.

This work is licensed under the Creative Commons Attribution International License (CC BY). http://creativecommons.org/licenses/by/4.0/

(c) (i) Open Access

\section{Abstract}

Depression and anxiety continue to be among the most common mental disorders. This study looked at three tracks of participants diagnosed with a mood disorder. The three tracks were Cognitive Therapy (CT), Mindfulness Training (MT), and Treatment As Usual (TAU). All participants had been trained in CT and then randomly separated into three groups. These three tracks were assessed at 3, 6, and 12 months in terms of their stated level of depression (measured on the Beck Depression Inventory) and anxiety (measured by the Beck Anxiety Inventory). This study was a follow-up to two previous studies (Alexander et al., 2012; Alexander \& Tatum, 2013). In the current study, the participants reported the tools and skills they used to manage their mood and anxiety and then the effectiveness of these tools/skills was examined. Two tools were identified by three independent coders as the most frequently used by the participants. Both of these tools related to thought management ("thought records" and "thought distortions"). The two tools were combined into a single category ("thought tools") and the frequency of their use was examined in relation to reductions in depression and anxiety. The results showed that a high use of these tools was connected to a significant reduction in reported depression. There was also a reduction in reported anxiety, but this effect was not statistically significant. Other tools that were reported (e.g., mood tracking, relaxation) showed no significant effects on depression and anxiety. Future research will now focus not on reported tool use, but rather on manipulating the incidence of tool use and determine the direct causal path between using a thought tool and reductions in negative moods.

\section{Keywords}

Depression, Cognitive Therapy, Mindfulness, Therapy Tools

\footnotetext{
${ }^{*}$ Corresponding author.
}

How to cite this paper: Alexander, V. L., \& Tatum, B. C. (2014). Effectiveness of Cognitive Therapy and Mindfulness Tools in Reducing Depression and Anxiety: A Mixed Method Study. Psychology, 5, 1702-1713. 


\section{Introduction}

Depression and anxiety are worldwide health problems. Recent statistics from the World Health Organization (2012) place depression as the leading cause of disability worldwide and affecting 350 million people of all ages and refers to depression and anxiety as two of the most prevalent non-communicable disorders. The Anxiety and Depression Association of America (2014) identify anxiety disorders as the most common disorder in the United States, affecting 40 million adults 18 and older and major depression affecting 14.8 million American adults.

\subsection{Depression, Anxiety, and Cognitive Therapy}

Studies on depression identify this mental disorder as treatable and research on Cognitive Therapy (CT) reveals a reduction in relapse and reoccurrence (Bockting et al., 2005; Fava, Grandi, Zielezny, Canestari, \& Morphy, 1996; Jarrett et al., 2001; Paykel et al., 1999). A complicating factor is the repeated relapse rates of $80 \%-90 \%$ (Chen, Jordan, \& Thompson, 2006; Judd, 1997) with the risk of chronic incapacity (Kennedy, Abbott, \& Paykel, 2003). The theory around CT is that the more the patients identify the relationship between their thoughts, feelings, and behavior, the better they will be able to modulate their emotional distress. Skills are taught with the supposition that if they acquire, comprehend, and practice these skills, they will have a reduction in symptoms. Although patients are taught CT skills, there are few measures available that assess how these tools promote cognitive and behavioral change. Some studies have identified measures to recognize the patients' awareness of automatic thoughts (Wright et al., 2002) or the comprehension and usage of the CT skills (Strunk, DeRubeis, Chiu, \& Alvarez, 2007). One group of researchers (Jarrett, Vittengl, Clark, \& Thase, 2011) developed their own measure to assess patients understanding and use of CT skills. Their findings supported their hypothesis that CT skills acquisition predicted a reduction in depressive symptoms.

Other research has demonstrated the efficacy of CT in reducing anxiety. For example, Wells (2002) viewed rumination as leading to avoidant behaviors and anxious thoughts. Matthew \& MacLeod (2005) associated anxiety with automatic thoughts that the individual feels is out of their control. The relationship between negative interpretation and a vulnerability toward developing an anxious mood was supported by Salemink, van den Hout, and Kindt (2010).

\subsection{Mindfulness}

The introduction of mindfulness into the CT model in prevention of relapse from depression was explored by Segal, Williams, \& Teasdale (2002). Clinical applications of mindfulness had already been adopted into therapeutic approaches such as Dialectical Behavioral Therapy (Linehan, 1993) and Acceptance and Commitment Therapy (Hayes, Strosahl, \& Wilson, 1999). Kabat-Zinn (1994) developed Mindfulness-Based Stress Reduction (MBSR) for pain management, yet MBSR began to be used for multiple chronic illnesses. Examples include eating disorders (Courbasson, Nishikawa, \& Shapira, 2011; Trapper et al., 2009), anxiety disorders (Roemer, Orstillo, \& Salters-Pedneault, 2008), posttraumatic stress disorder (Owen, Walter, Chard, \& Davis, 2012; Wolfsdorf \& Zlotnick, 2001), and substance abuse (Courbasson, Nishikawa, \& Shapiro, 2011). Deyo, Wilson, Ong, \& Koopman (2009) also found MBSR to have a decrease in rumination in individuals with depressive symptoms. Hofman, Sawyer, Witt, \& Oh (2010) reviewed studies of participants receiving mindfulness based treatment for a range of conditions. Their finding found a significant anxiety reduction and mood symptom improvement. Keng, Smoski, \& Robins (2011) also demonstrated mindfulness in managing depression and anxiety by identifying ruminations and other cognitive processes which exacerbate and maintain the symptoms.

Mindfulness awareness has been shown to enhance one's sense of well-being by learning to modulate emotions effectively (Lau et al., 2006). The principles of mindfulness have enjoyed increased attention in the psychological literature and psychotherapy practice, moving from a Buddhist concept of understanding mental processes of impermanence, non-attachment, and letting go (Khong, 2009) to a mainstream construct in therapy viewing the subjective, fluid, and temporary nature of mental states that impact emotional regulation and cognitive flexibility (Wallin, 2007).

The purpose of this study was to identify if there were specific tools that the patients learned that they continued to use to manage their depression and anxiety to prevent relapse. This is an exploratory sequential mixed (qualitative and quantitative) method approach (Creswell, 2014) designed as a follow-up investigation of two previously published studies (Alexander et al., 2012; Alexander \& Tatum, 2013). In Alexander et al., 2012, 
mindfulness practices and cognitive therapy were found to reduce depression and increase mindful and generalized self-efficacy in two tracks which continued to be trained in these tools post discharge from an outpatient program for depression. In Alexander \& Tatum, 2013, the study utilized qualitative statements from participants on which of the cognitive therapy and/or mindfulness tools they consistently used to manage their symptoms of depression. From 17 tools/skills identified, three sets of tools were used consistently and significantly across all three tracks. These were a) catching and refuting thought distortions; b) examining thought records; and c) an activity schedule (GRAPES).

\section{Method}

\subsection{Research Setting and Design}

This study originated at a West Coast psychiatric hospital outpatient program in a large urban city. Patients were assigned to three treatment tracks and followed at regular intervals for up to one year after discharge from the Cognitive Intensive Outpatient program (COGIOP). The COGIOP was attended by adults whose primary diagnosis was a Mood Disorder and often a step down from inpatient hospitalization. The primary treatment modality for the COGIOP was CT and patients typically attended the five day a week program for six weeks. The three treatment tracks that followed the COGIOP were a) a continuation of CT; b) Mindfulness Training (MT); and c) Treatment as Usual (TAU). Patients were administered two questionnaires (for reported depression and anxiety) and asked two open-ended questions (about the use of cognitive tools) at 3, 6, and 12 months.

\subsection{Participants}

The participants were 201 patients who attended the COGIOP for at least 20 sessions. All were diagnosed with at least one episode of Major Depression or Bipolar Disorder, Currently Depressed, as defined by the Diagnostic and Statistical Manual of Mental Disorder-IV-TR (American Psychological Association, 2000). Current levels of depression were less than 20 on the Beck Depression Inventory (Beck, Steer, \& Brown, 1996). This cut-off score was seen as an indication of the participants' capacity to concentrate and be able to focus on mindful exercises. The demographic information was collected separately and only 82 of the 201 responded. Of these individuals, forty-five percent were between 38 and 52 years of age, $72 \%$ were female, $40 \%$ married, $83 \%$ Caucasian, and 54\% Christian. All had at least a high school education and 66\% had a bachelor's degree or higher. One hundred percent were diagnosed with a Mood Disorder (80\% Major Depression and 20\% Bipolar, Currently Depressed). Fifty-two reported an additional diagnosis of an Anxiety Disorder, 52\% had had seven or more bouts of depression prior to the COGIOP, $89 \%$ were still on antidepressant medication, and $9 \%$ had been hospitalized since they left the program.

\subsection{Measures}

Beck Depression Inventory (BDI). The BDI (Beck et al., 1996) is a 21-item self-report questionnaire that measures attitudes and symptom characteristics of the diagnosis of depression. Patients rated these symptoms such as "I don't sleep as well as I used to" or "I cry all the time now" on a scale of 0 (not at all) to 3 (all the time). Patients can score between 0 - 63. Participants in the aftercare tracks were required to have a BDI less than 20 at the day of discharge to be in the study. Scores ranged from zero (0) to three (3) when averaged across all 21 items. The BDI was completed at discharge from the COGIOP and at 3, 6, and 12 months.

Burns Anxiety Inventory (BAI). The BAI (Burns, 1999) is a 33-item self-report questionnaire that measures subjective expressions of anxiety emotionally (e.g., "feeling tense, stressed, 'uptight' or on edge”), cognitively (e.g., “difficulty concentrating”), and physically (e.g., "pain, pressure or tightness in the chest”). Each item is rated on a 0 (not at all) to 3 (a lot) scale. Patients can score between 0 - 99. Scores ranged from zero (0) to three (3) when averaged across all 33 items. The BAI was also completed at discharge from the COGIOP and at 3, 6, and 12 months.

Open-Ended Questions. All of the participants were followed up with a survey mailed to them at 3, 6, and 12 months, in a return self-addressed stamped envelope. The survey consisted of two open-ended, qualitative questions:

1) Have you continued to use cognitive tools which you learned in the program and/or in the four Monday evening sessions? If so, which tools have you continued to use? 
2) Are you practicing mindfulness? If so, how often and what types of practice are you using?

\subsection{Procedure}

Patients who attended a minimum of 20 treatment days in the COGIOP and had a BDI score less than 20 were eligible for this aftercare study. All of the patients volunteered, signed an informed consent, and were randomly assigned to one of three tracks. The first track was the CT track. Patients assigned to this track attended a three hour, once a week session for four weeks with a focus on relapse prevention. Their format was the same as the COGIOP, where the first hour was psycho-educational followed by a 15 minute break and a 1 hour 45 minute group session. Patients reviewed CT techniques and skills. This track was taught by therapists trained in the principles of CT.

The second track was the MT. Participants attended a three hour, once a week for four weeks session, where the focus was on learning mindfulness practice. All of the participants in this track engaged in three hour mindfulness education and practice and listened daily to a 30-minute CD which consisted of mindful breathing exercises and focused on sensations in various parts of their bodies with awareness and non-judgment. Patients were further educated to mindfulness principles of letting go, staying in the present, and viewing thoughts as mental events and not facts. This track was facilitated by trained therapists with their own mindfulness practice.

The third track was the TAU and was comprised of patients who were discharged from COGIOP and followed up with outpatient therapists and/or psychiatrist.

Three independent coders, who were knowledgeable in the COGIOP program, read the patients responses to the open-ended items on the survey and placed them into 17 tool categories. The inter-rater agreement for the coders was between $80 \%-90 \%$. For a complete list and description of the 17 categories, refer to Alexander and Tatum (2013) and Appendix C.

\section{Results}

Table 1 is based, in part, on results reported by Alexander and Tatum (2013) and displays the average BDI, average BAI, and the two most frequent tools reported by the CT, MT, and TAU study participants across 3,6 , and 12 months. The tools are listed according to the percentage of times they were reported. Two sets of tools stood out as being used consistently across all three tracks (CT, MT, and TAU). These standouts were Thought Records (named as the most frequently used tool four times) and Thought Distortion (named as the most frequently used tool three times). Direct quotations from patients' surveys are included in Appendix A and more detail on the tools are in Appendix B.

The reporting of Thought Records and Thought Distortion as frequently used tools does not mean, however, that these tools were useful in helping to reduce depression or anxiety. Therefore, we did an analysis of the effectiveness of these tools. The strategy for these analyses was to examine whether low, moderate, and high use of the thought tools (Thought Records and Thought Distortions) was related to changes in depression or anxiety. First, we combined the Thought Records and the Thought Distortions into a single tool (what we called the "Thought Tools"). Then, we divided the Thought Tools into low, moderate, and high use categories. We defined these categories such that there were roughly equal numbers of patients in each category for the CT, MT, and TAU tracks. Specifically, low use of the tools was defined as selecting the tool, on average, zero or one time only, moderate use was when the average selection of the tool was more than once but not more than two times, and high use was three or more selections on average. We then performed an analysis of covariance (ANCOVA) with the average depression (BDI) for month three as the dependent variable and the pretest for anxiety (BAI) as the covariate. (We did not analyze the 6 and 12 month BDIs because attrition reduced the sample sizes and the data became unstable.) We performed another ANCOVA with the average anxiety (BAI) for month three as the dependent variable and the pretest depression (BDI) as the covariate (again, months 6 and 12 were unstable). Both ANCOVAs (See Table 2) used Treatment Track (CT, MT, and TAU) and Thought Tools (low, moderate, and high) as independent variables.

The results of the two ANCOVAs showed that the use of the tools did have a significant effect on depression but not on anxiety. The first ANCOVA, using depression as the dependent variable, revealed an interaction between Treatment Track and Thought Tools $(\mathrm{F}[4,73]=2.56, \mathrm{p}<.05$, MSE $=.196$, Eta-square $=.196)$. Close inspection of the results indicated that increasing use of the tools had a large effect on the CT patients, a somewhat smaller effect on the MT patients, and no effect at all for TAU. Specifically, the increasing use of the Thought 
Table 1. Beck depression index (BDI) and Burns anxiety index (BAI) scores (averaged across items) and tool use (thought records and thought distortions) across tracks and months.

\begin{tabular}{|c|c|c|c|}
\hline & Cognitive Track & Mindfulness Track & Treatment as Usual Track \\
\hline \multirow{7}{*}{3 month } & $\underline{\mathrm{BDI}}$ & $\underline{\mathrm{BDI}}$ & $\underline{\mathrm{BDI}}$ \\
\hline & $\overline{1.86}$ & $\overline{1.47}$ & $\overline{1.83}$ \\
\hline & $\underline{\mathrm{BAI}}$ & $\underline{\mathrm{BAI}}$ & $\underline{\mathrm{BAI}}$ \\
\hline & 2.22 & 1.71 & 1.71 \\
\hline & $\underline{\text { Tool }}$ & $\underline{\text { Tool }}$ & $\underline{\text { Tool }}$ \\
\hline & Thought Records (25\%) & Thought Distortions (13\%) & Thought Records (14\%) \\
\hline & Thought Distortions (14\%) & Thought Records (11\%) & Thought Distortions (13\%) \\
\hline \multirow{7}{*}{6 month } & $\underline{\mathrm{BDI}}$ & $\underline{\mathrm{BDI}}$ & $\underline{\mathrm{BDI}}$ \\
\hline & $\overline{1.59}$ & $\overline{1.41}$ & $\overline{1.50}$ \\
\hline & $\underline{\mathrm{BAI}}$ & $\underline{\mathrm{BAI}}$ & $\underline{\mathrm{BAI}}$ \\
\hline & 2.01 & 1.62 & 1.77 \\
\hline & Tool & Tool & $\underline{\text { Tool }}$ \\
\hline & Thought Records (20\%) & Thought Records (13\%) & Thought Distortions (20\%) \\
\hline & Thought Distortions (6\%) & Thought Distortions (12\%) & Thought Records (10\%) \\
\hline \multirow{7}{*}{12 month } & $\underline{\mathrm{BDI}}$ & $\underline{\mathrm{BDI}}$ & $\underline{\mathrm{BDI}}$ \\
\hline & $\overline{1.17}$ & $\overline{.99}$ & $\overline{1.47}$ \\
\hline & $\underline{\mathrm{BAI}}$ & $\underline{\mathrm{BAI}}$ & $\underline{\mathrm{BAI}}$ \\
\hline & $\overline{1.86}$ & $\overline{1.38}$ & $\overline{1.62}$ \\
\hline & Tool & Tool & Tool \\
\hline & Thought Records (18\%) & Thought Distortions (21\%) & Thought Distortions (17\%) \\
\hline & Thought Distortions (9\%) & Thought Records (15\%) & Thought records (11\%) \\
\hline
\end{tabular}

Note: Percentages indicate the percentage of patients reporting using that tool.

Table 2. ANCOVAs used to test the effects of thought tools (low, moderate, and high) and track (CT, MT, and TAU) on depression and anxiety.

\begin{tabular}{ccccc}
\hline Dependent Variable & Interaction F value & $p$ value & MSE & Eta square \\
\hline Depression & 2.56 & $<.05$ & .196 & .196 \\
Anxiety & 1.78 & $>.05$ & .264 & .090 \\
\hline
\end{tabular}

Tools lowered the reported depression for CT and MT, but had no effect for TAU.

The second ANCOVA, using anxiety as the dependent variable, did not reveal an interaction between Treatment Track and Thought Tools $(\mathrm{F}[4,73]=1.78 \mathrm{p}>.05$, MSE $=.264$, Eta-square $=.09)$. Close inspection of the results showed a pattern similar to that of depression (i.e., a larger effect for the CT track than for the MT track, but no effect for TAU), but the power of the test was insufficient to yield a statistically significant effect.

It might be argued that increasing the use of any tools might lower depression and anxiety, so we conducted two additional ANCOVAs similar to the two above. However, with these ANCOVAs we replaced the Thought Tools with low, moderate, and high use categories of all the remaining tools combined (e.g., mood tracking, anger management, relaxation). Neither of these additional ANCOVAs produced any significant effects. For depression, the interaction between Treatment Track and non-thought tools was $\mathrm{F}(4,73)=.20$, MSE $=.244$, Etasquare $=.01$, and for anxiety the interaction was $\mathrm{F}(4,73)=.96$, MSE $=.288$, Eta-square $=.05$.

\section{Discussion}

This discussion will not dwell on the average BDI and BAI results and will focus mainly on tool use and its relation to depression and anxiety. The general trend for the third month was that the CT group received the largest benefit from using the thought-related tools. There was a significant reduction in depression for the CT group when they used these tools. There was a smaller reduction in depression for the MT group, but the effect was 
significant. There was no effect of thought tool use for the TAU group. The effect of the thought tools on anxiety was similar to that of depression (i.e., anxiety was lowered when the thought tools were used) but the effects were not statistically significant. The use of other tools such as mood tracking and relaxation had no effect on depression and anxiety.

These findings need to be interpreted with a bit of caution due to the non-experimental nature of the study. We did not manipulate the use of the tool. Rather, we acquired self reports of the tool use. It is possible that those patients who reported more use of the tools were the same patients who experienced the lowest levels of depression and anxiety. We attempted to control for this possibility by using their pre-treatment depression and anxiety scores as covariates, but this may not have been a sufficient control. Ideally, these tools should be independently manipulated and the effects of high and low levels studied in a more control, true experimental way. Nevertheless, the study is important is showing that there is a connection between the use of these tools and the reported levels of depression and anxiety.

It was notable that of all the 17 skills/tools identified by the independent coders, Thought Records and Thought Distortions were at the top of the list of reported tools. This gave validity to the CT tools of catching and disputing thought distortions and using thought records in managing symptoms of depression and anxiety. Thought distortions that the participants were trained to identify are in Appendix B. Participants reported that they were better able to identify these distortions and take a step back without the emotional reaction.

The thought records similarly required the patient to recognize their negative distortions and examine the evidence for and against the thought creating emotional distress. Patients were trained to write down the thought that contributed to a negative shift in mood and then examine the facts that both supported and negated the thought. For example: you found out you did not get a job you interviewed for and say "I am such a loser". What are the facts that support this statement and those that negate it? CT assisted the patients in decentering from the thought and assessed the validity. The premise was to come up with a balanced thought. As in the example just stated "I am a loser" a balanced thought would be that "I don't do everything faultlessly but there is much I do well".

It is interesting that the patients in the MT group showed a high frequency of reporting thought tools characterized by CT, but did not report many tools specific to MT. Current literature has highlighted the difficulty in defining the construct of mindfulness in self-report questionnaires (Baer, Smith, \& Allen, 2004) and in selfreport assessment (Grossman, 2011). The understanding of a construct such as being in the moment or nonjudgmental awareness will differ from those with experience in mindfulness and those who are novices (Grossman, 2011). In the returned surveys, participants used the term mindfulness as a broader concept instead of identifying specific behaviors such as focus on the breath or awareness of body sensations. For the purpose of this study, patients in the MT had training by therapists with their own mindfulness practice and reportedly practiced the awareness of the breath and body sensations along with an understanding of mindfulness as living in the moment, without judgment. Both CT and MT have been shown to enhance emotional regulation (Corcoran, Farb, Anderson, \& Segal, 2010; Farb et al., 2010) and decrease rumination via disengagement from the cognitive processes (Cambers, Lo, \& Allen, 2008). In this sense it may be difficult for the patient to specifically identify which skill they are using. As one participants stated "I am not able to explain the exact tools I use but can say that the combination of the months I spent in the program learning these tools changed my life". While the participants in the MT engaged in 30 min. per day practice, researchers in both MBSR and MBCT (Mindfulness Based Cognitive Therapy) recommended that patients engaged in 45 minutes of daily mindful practice (Kabat-Zinn, 1994; Teasdale et al., 2000). Thus the reduced time of this practice for the study participants may have mitigated against a more vigorous and consistent integration of the practice into their daily lives and a lower reporting of MT-specific tools.

Appendix A includes direct statements from the participants returned surveys. While many reported the benefits of the program or the tools learned and practiced, it was also apparent that this was/is a continual process, that lapses occur, that patients may continue to benefit from medication in conjunction with CT or MT, and that tools do not eliminate life stressors. However, as one participant stated "Learning these tools saved my life. Things are still quite difficult but I am managing.”

Further research should attempt to find more sensitive ways to identify tool use from patients receiving mindfulness training. These patients may be using MT-related tools, but the self-report technique does not seem to allow them to articulate what they are in a way that researchers can identify and use. Additional studies should also focus on those patients with a diagnosis of Bipolar Disorder, Currently Depressed to further research 
the use of CT and MT for the management of symptoms of this diagnosis. Another area of research is to assess is the level of anxiety reported by Bipolar Disorder, Currently Depressed patients and examine the relationships between anxiety and depression with this population.

\section{Conclusion}

Mindfulness and CT continue to be researched and utilized in treatment of depression and anxiety. While this study has brought attention to two tools and skills in CT (thought records and thought distortions) that patients reported they consistently used to manage their mood state, it was also evident that treatment is unique to each individual and that clinicians need to find not only what is most beneficial for their patients but what are the skills and tools that they will continue to use. The patients in this study continued to benefit from the use of thought records and catching and disputing thought distortions. The formats for these tools are included in Appendix B.

\section{References}

Alexander, V., \& Tatum, B. C (2013). A Qualitative Analysis of Mindfulness Practice and Cognitive Therapy Tools in Preventing Relapse from Depression. Journal of Education Research and Behavioral Sciences, 2, 98-106.

Alexander, V., Tatum, B. C., Auth, C., Takos, D., Whittemore, S., \& Fidaleo, R. (2012). A Study of Mindfulness Practices and Cognitive Therapy: Effects on Depression and Self-Efficacy. International Journal of Psychology and Counselling, 4, 115-122. http://dx.doi.org/10.5897/IJPC

American Psychiatric Association (2000). Diagnostic and Statistical Manual of Mental Disorders IV-Text Revised. Washington DC: Author.

Anxiety and Depression Association of America (2014). Facts and Statistics. www.adaa.org

Baer. R. A., Smith, G. T., \& Allen, K. B. (2004). Assessment of Mindfulness by Self-Report: The Kentucky Inventory of Mindfulness Skills. Assessment, 11, 191-206. http://dx.doi.org/10.1177/1073191104268029

Beck, A. T., Steer, R. A., \& Brown, G. K. (1996). Beck Depression Inventory (2nd ed.). San Antonio TX: The Psychological Corporation.

Bockting, C. L. H., Schene, A. H., Koeter, M., Wouters, L., Huyser, J., \& Kamphuis, J. H. (2005). Preventing relapse/Reoccurrence in Recurrent Depression with Cognitive Therapy: A Randomized Controlled Trial. Journal of Consulting and Clinical Psychology, 73, 647-657. http://dx.doi.org/10.1037/0022-006X.73.4.647

Burns, D. (1999). The Feeling Good Handbook (rev. ed.). New York, NY: Plume.

Chambers, R., Lo, B. C. Y., \& Allen, N. B. (2008). The Impact of Intensive Mindfulness Training on Attentional Control, Cognitive Style, and Affect. Cognitive Therapy and Research, 32, 303-322.

Chen, S. Y., Jordan, C., \& Thompson, S. (2006). The Effect of Cognitive Behavioral Therapy on Depression: The Role of Problem-Solving Appraisal. Research in Social Work Practice, 16, 500-510. http://dx.doi.org/10.1177/1049731506287302

Corcoran, K. M., Farb, N., Anderson, A., \& Segal, Z. V. (2010). Mindfulness and Emotion Regulation: Outcomes and Possible Mediating Mechanisms. In A. M. Kring, \& D. M. Sloan (Eds.), Emotion Regulation and Psychopathology: A Transdiagnostic Approach to Etiology and Treatment (pp. 339-355). New York: Guilford Press.

Courbasson, C. M., Nishikawa, Y., \& Shapira, L. B. (2011). Mindfulness-Action Based Cognitive Behavioral Therapy for Concurrent Binge Eating Disorder and Substance Use Disorders. Eating Disorders, 19, 17-33. http://dx.doi.org/10.1080/10640266.2011.533603

Creswell, J. W. (2014). Research Design: Qualitative, Quantitative and Mixed Methods Approaches (4th ed.). Thousand Oaks, CA: Sage.

Deyo, M., Wilson, K. A., Ong, J., \& Koopman, C. (2009). Mindfulness and Rumination: Does Mindfulness Training Lead to Reductions in the Ruminative Thinking Associated with Depression? Explore, 5, 265-271.

http://dx.doi.org/10.1016/j.explore.2009.06.005

Farb, N. A. S., Anderson, A. K., Mayberg, H., Bean, J., McKeon, D., \& Segal, Z. V. (2010). Minding One’s Emotions: Mindfulness Training Alters the Neural Expression of Sadness. Emotion, 10, 25-33. http://dx.doi.org/10.1037/a0017151.supp

Fava, G., Grandi, S., Zielezny, M., Canestari, R., \& Morphy, M. A. (1996). Cognitive Behavioral Treatment of Residual Symptoms in Primary Major Depressive Disorder. American Journal of Psychiatry, 151, 1295-1299.

Grossman, P. (2011). Defining Mindfulness by How Poorly I Think I Pay Attention during Everyday Awareness and Other Intractable Problems in Psychology's Reinvention of Mindfulness: Comment on Brown et al. 2011. Psychological As- 
sessment, 23, 1034-1040. http://dx.doi.org/10.1037/a0022713

Hayes, S. C., Strosahl, K. D., \& Wilson, K. G. (1999). Acceptance and Commitment Therapy: An Experiential Approach to Behavior Change. New York: Guilford Press.

Hofman, S. G., Sawyer, A. T., Witt, A. A., \& Oh, D. (2010). The Effect of Mindfulness Based Therapy on Anxiety and Depression: A Meta-Analytic Review. Journal of Consulting and Clinical Psychology, 78, 169-183. http://dx.doi.org/10.1037/a0018555

Jarrett, R. B., Kraft, D., Doyle, J., Foster, B. M., Eaves, G. G., \& Silver, P. C. (2001). Preventing Recurrent Depression Using Cognitive Therapy with and without a Continuation Phase: A Randomized Clinical Trial. Archives of General Psychiatry, 58, 381-388. http://dx.doi.org/10.1001/archpsyc.58.4.381

Jarrett, R. B., Vittengl, J. R., Clark, L. A., \& Thase, M. E. (2011). Skills of Cognitive Therapy (SoCT): A New Measure of Patients' Comprehension and Use. Psychological Assessment, 23, 578-586. http://dx.doi.org/10.1037/a0022485

Judd, L. J. (1997). The Clinical Course of Unipolar Depressive Disorders. Archives of General Psychiatry, 54, 989-991. http://dx.doi.org/10.1001/archpsyc.1997.01830230015002

Kabat-Zinn, J. (1994). Wherever You Go, There You Are: Mindfulness Meditation in Everyday Life. New York: Hyperion.

Keng, S. L., Smoski, M. J., \& Robins, C. J. (2011). Effects of Mindfulness on Psychological Health: A Review of Empirical Studies. Clinical Psychological Review, 31, 1041-1056. http://dx.doi.org/10.1016/j.cpr.2011.04.006

Kennedy, N., Abbott, R., \& Paykel, E. S. (2003). Remission and Reoccurrence of Depression in a Maintenance Era: Long-Term Outcome in a Cambridge Cohort. Psychological Medicine, 33, 827-838.

http://dx.doi.org/10.1017/S003329170300744X

Khong, B. S. L. (2009). Expanding the Understanding of Mindfulness: Seeing the Tree and the Forest. The Humanist Psychologist, 37, 117-136. http://dx.doi.org/10.1080/08873260902892006

Lau, M. A., Bishop, S. R., Segal, Z. V., Buis, T., Anderson, N., Carlson, L., Shapiro, S., \& Carmody, J. (2006). The Toronto Mindfulness Scale: Development and Validation. Journal of Clinical Psychology, 62, 1445-1467. http://dx.doi.org/10.1002/jclp.20326

Linehan, M. M. (1993). Cognitive-Behavioral Treatment of Borderline Personality Disorder. New York: Guilford.

Matthew, A. \& MacLeod, C. (2005). Cognitive Vulnerability to Emotional Disorders. Annual Review of Clinical Psychology, 1, 167-195. http://dx.doi.org/10.1146/annurev.clinpsy.1.102803.143916

Owen, G. P., Walter, K. H., Chard, K. M., \& Davis, P. A. (2012) Changes in Mindfulness Skills and Treatment Response among Veterans in Residential PTSD Treatment. Psychological Trauma: Theory, Research, Practice and Policy, 4, 221228. http://dx.doi.org/10.1037/a0024251

Paykel, E. S., Scott, J., Teasdale, J. D., Johnson, A. L., Garland, A., \& Moore, R. (1999). Prevention of Residual Depression by Cognitive Therapy: A Controlled Trial. Archives of General Psychiatry, 56, 829-835.

http://dx.doi.org/10.1001/archpsyc.56.9.829

Roemer, L., Orsillo, S. M., \& Salters-Pedneault, K. (2008). Efficacy of an Acceptance-Based Behavior Therapy for Generalized Anxiety Disorder: Evaluation in a Randomized Controlled Trial. Journal of Consulting Clinical Psychology, 76, 1083-1089. http://dx.doi.org/10.1037/a0012720

Salemink, E., van den Hout, M., \& Kindt, M. (2010). How Does Cognitive Bias Modification Affect Anxiety? Mediation Analysis and Experimental Data. Behavioral and Cognitive Psychotherapy, 38, 59-66. http://dx.doi.org/10.1017/S1352465809990543

Segal, Z. V., Williams, J. M. G., \& Teasdale, J. D. (2002). Mindfulness-Based Cognitive Therapy for Depression: A New Approach to Preventing Relapse. New York: Guilford Press.

Strunk, D. R., DeRubeis, R. J., Chiu, A. W., \& Alvarez, J. (2007). Patients'Competence in the Performance of Cognitive Therapy Skills: Relation to the Reduction of Relapse Risk Following Treatment for Depression. Journal of Consulting and Clinical Psychology, 75, 523-530. http://dx.doi.org/10.1037/0022-006X.75.4.523

Teasdale, J. D., Williams, J. M., Soulsby, J. M., Segal, Z. V., Ridgeway, V. A., \& Lau, M. A. (2000). Prevention of Relapse/Recurrence in Major Depression by Mindfulness-Based Cognitive Therapy. Journal of Consulting and Clinical Psychology, 68, 615-623. http://dx.doi.org/10.1037/0022-006X.68.4.615

Trapper, K., Shaw, C., Illsey, J., Hill, A. J., Bond, F. W., \& Moore, L. (2009). Exploratory Randomized Controlled Trial of a Mindfulness-Based Weight Loss Prevention for Women. Appetite, 52, 396-404. http://dx.doi.org/10.1016/j.appet.2008.11.012

Wallin, D. J. (2007). Attachment in Psychotherapy. New York: Guilford Press.

Wells, A. (2002). GAD, Metacognition and Mindfulness: An Information Processing Analysis. Clinical Psychology: Science \& Practice, 9, 95-100. http://dx.doi.org/10.1093/clipsy/9.1.95 
Wolfsdorf, B. A., \& Zlotnick, C. (2001). Affect Management in Group Therapy for Women with Posttaumatic Stress Disorder and Histories of Childhood Sexual Abuse. Journal of Clinical Psychology, 57, 169-181.

http://dx.doi.org/10.1002/1097-4679(200102)57:2<169::AID-JCLP4>3.0.CO;2-0

World Health Organization (2012). Fact Sheet on Depression. www.who.int/topics/depression/en

Wright, J. H., Wright, A. S., Salmon, P., Beck, A. T., Kuykendall, J., Goldsmith, L. J., \& Zickel, M. B. (2002). Development and Initial Testing of a Multimedia Program for Computer-Assisted Cognitive Therapy. American Journal of Psychotherapy, 56, 76-86. 


\section{Appendix A}

Statements of Tool Use by Participants

CT: "I'm better able to be objective/detached about a situation I would have overreacted to in the past. Also I am better at noticing when I'm negatively judging myself and my emotions and can stop it."

CT: "I have never been happier in my life and can actually say that 'cog therapy' works; it is not the medication (although it helps) but it is the understanding of our psyche... You can use me as an example that cog works. It was very difficult to cope with life before due to my upbringing and culture. But now I am totally different person, I take responsibility for my actions, I can see clear my future.”

CT: "The return to the work environment has been stressful but I manage using different COG tools. I think about my time in the program and it was the best, healthiest thing I have ever done for myself."

CT: "I'm going through a bit of a lapse right now and am trying to use the tools from COG to fight it. So far I am doing fine."

CT: "I really learned to be aware of my distorted thoughts. There's constantly an alarm going off in my head when one comes across. Before, I was completely unaware of my distorted thoughts.”

MT: "Thought stopping, relaxation, mindfulness, and mental thought records. I repeat new core beliefs mentally when anxiety increases or old core beliefs raise their ugly head."

MT: "I am dealing with my anxiety in a positive way and I am going to be OK no matter what because I have come to the realization that every moment is precious and I intend to live and experience these moments as they may never come again. I want to say I lived my life and not my life happened.”

MT: "Learning these tools saved my life. Things are still quite difficult but I am managing."

MT: "I believe the cognitive therapy skills and group and mindfulness meditation techniques changed my life for the better. I learned how to think and act and respond in healthy ways and how to know and respect myself and how to protect myself."

MT: "I understand the importance of...staying on top of unpleasant thoughts. I have been avoiding using some of the techniques and saw my mood drop. I feel as though they were great things to learn.”

MT: "I've been feeling quite well... Anytime I feel I am slipping a bit, I just analyze things like a thought record or de-catastophizing worksheet. Bad thoughts just don't last.”

MT: "Life still has some real challenges. Now I face them and deal with them. I can still improve in some areas of my life, but I no longer tear myself up for my shortcomings. I have the tools and the abilities to have a really cool life and I look forward to living it instead of fearing it all the time."

TAU: "I strongly rely on the cognitive tools. This program saved my life and made it better."

TAU: "This program really helped. I wish I had known about it before life got so bad. It is one of the main components to me dealing with depression..."

TAU: "I have had increasing success in recognizing distorted thoughts as distorted, recognizing the types of avoidant or reactionary behaviors I "automatically" adopt in response to cognitive distortions, and taking the time/energy to challenge and change thought/behavior patterns that keep me locked in cycles of distorted thinking behaviors."

TAU: "I no longer have thoughts of suicide because I now know why I was having these thoughts. I do not suffer from depression. Every day I look happily forward.”

TAU: "Cognitive Therapy continues to be a big part of my life and feeling of successfully being able to function."

TAU: "Reframing my thoughts if they are negative, I am learning to be loving and compassionate with myself. This is a new way of living for me."

TAU: "I am not able to explain the exact tools I use but can say that the combination of the months I spent in the program learning these tools changed my life. I've worked pretty hard on some old issues that have been quite challenging. While going through them was quite painful it was healing and an ongoing process. I am taking it slow and can feel the progress.”

\section{Appendix B}

Tools Used Most Consistently by Participants

THOUGHT DISTORTIONS: Through training in identifying thought distortions such as all or nothing thinking (see examples in Appendix A), patients were able to increase their awareness of their faulty thinking and 
come up with more balanced thoughts

1. All or nothing thinking (thinking in extremes)

2. Minimizing or magnification (exaggerate negative factors and dilute positive factors)

3. Overgeneralization (sweeping judgments on a single event)

4. Filtering (focusing on one aspect of a situation, typically the negative aspect)

5. Catastrophizing (thinking that the worst case scenario will come true)

6. Personalization (taking responsibility for things that don't apply to you)

7. Jumping to conclusions (making negative assumptions without the evidence to support this)

8. Labeling (assigning labels to self or others)

9. Should statement (rigid unrealistic rules of self and others)

Participants reported that they were better able to identify these distortions and take a step back without the emotional reaction.

\section{THOUGHT RECORD}

\begin{tabular}{ccccc}
\hline Situation & $\begin{array}{c}\text { Automatic } \\
\text { Thought }\end{array}$ & Emotion & $\begin{array}{c}\text { Rating } \\
(0 \%-100 \%)\end{array}$ & $\begin{array}{c}\text { Rational } \\
\text { Response }\end{array}$ \\
\hline
\end{tabular}

\section{Test of Evidence}

Evidence Thought is not 100\% True 
1. When you experience a shift in mood, what is the situation?

2. Identify the emotion you are experiencing such as depression, anger, anxiety. One emotion per thought record.

3. Rate the emotion on a scale from $0 \%-100 \%(100=$ most extreme, $0=$ absence of the emotion).

4. Identify the thought that is causing this elevated rating in mood. If there are several thoughts, choose the most extreme.

5. Evidence the thought is true: Come up with as many facts as you can that support the thought.

6. Dispute the thought: What is the evidence the thought is not true.

7. After disputing the thought, identify a more rational thought.

8. Re-rate the intensity of the emotion.

\section{Appendix C}

The 17 Tools

1. Mood tracking/daily inventory: A brief inventory with ten items, measuring the patient's level of depression that day and charted to show fluctuations in daily mood.

2. Conflict resolution worksheets: Healthy and unhealthy ways of managing and resolving conflict worksheets.

3. Thought records: Examining the situation, thoughts, feelings, and behaviors. What is the evidence that the thought is true and what is the evidence the thought is not true? The goal is to come up with a more balanced thought.

4. Thought distortions: Identifying faulty thinking and changing it.

5. Activity Schedule (GRAPES): A worksheet that lists daily activities related to G (gentle with self), R (relaxation), A (accomplishments), P (pleasure), E (exercise), and S (social).

6. Assertiveness script (DEESC): Write out a script to increase assertive behavior. D (describe problem), E (express emotions), E (empathy; how does this impact the other person), S ( specifics; i.e. I want ...or I need...), $\mathrm{C}$ ( consequences; if ...then...).

7. Core belief/Schema work: Beliefs about ourselves, others, and the world from early experiences which is the way in which we interpret and process situations. Core belief work assists the patients in identifying their personal beliefs which make them vulnerable to depression.

8. Journaling: A log of our beliefs and feelings at the present moment to have a better understanding of how we are interpreting information and events.

9. Responsibility pie: To process our role in a situation. If the situation or event were a piece of pie, how big would your role be? Who else would be involved in the event and what would their roles be?

10. Boundaries: Discussing behaviors indicative of fluid, healthy, and rigid boundaries.

11. Distractions: Ways to remove ourselves from difficult emotional states such as counting backwards by 7 .

12. Motivation model: Action leads to motivation which leads to more action. Examining the pros and cons of avoidance and action.

13. Pros/Cons worksheet: Problem identification, brainstorming possible solutions, and listing the pros and cons of each option.

14. Decatastrophizing worksheet: Identifying the situation creating anxiety and one's belief about the danger. The worksheet examines the evidence of support and refutes the belief about the danger (my job is at risk) and about one's control (there is nothing I can do about it).

15. Anger management: RETHINK model. R (recognize that you are feeling angry), E (empathize with the person or situation causing the anger), $\mathrm{T}$ (think instead of just emoting), $\mathrm{H}$ (hear what the other person is saying), I (integrate respect but thinking in a non-angry way), $\mathrm{N}$ (notice your body's reaction to anger), K (keep focused on the present event and not past grudges. Think of solutions).

16. Relaxation techniques: Imagery, diaphragmatic breathing, and progressive muscle relaxation.

17. Mindfulness: Of being in the moment, practicing letting go, increasing awareness without judgment, focus on the breath and body awareness. 
Scientific Research Publishing (SCIRP) is one of the largest Open Access journal publishers. It is currently publishing more than 200 open access, online, peer-reviewed journals covering a wide range of academic disciplines. SCIRP serves the worldwide academic communities and contributes to the progress and application of science with its publication.

Other selected journals from SCIRP are listed as below. Submit your manuscript to us via either submit@scirp.org or Online Submission Portal.
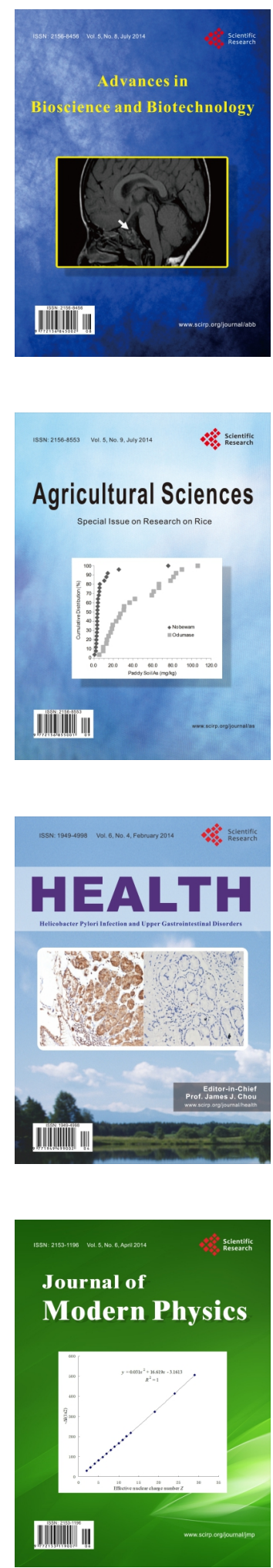
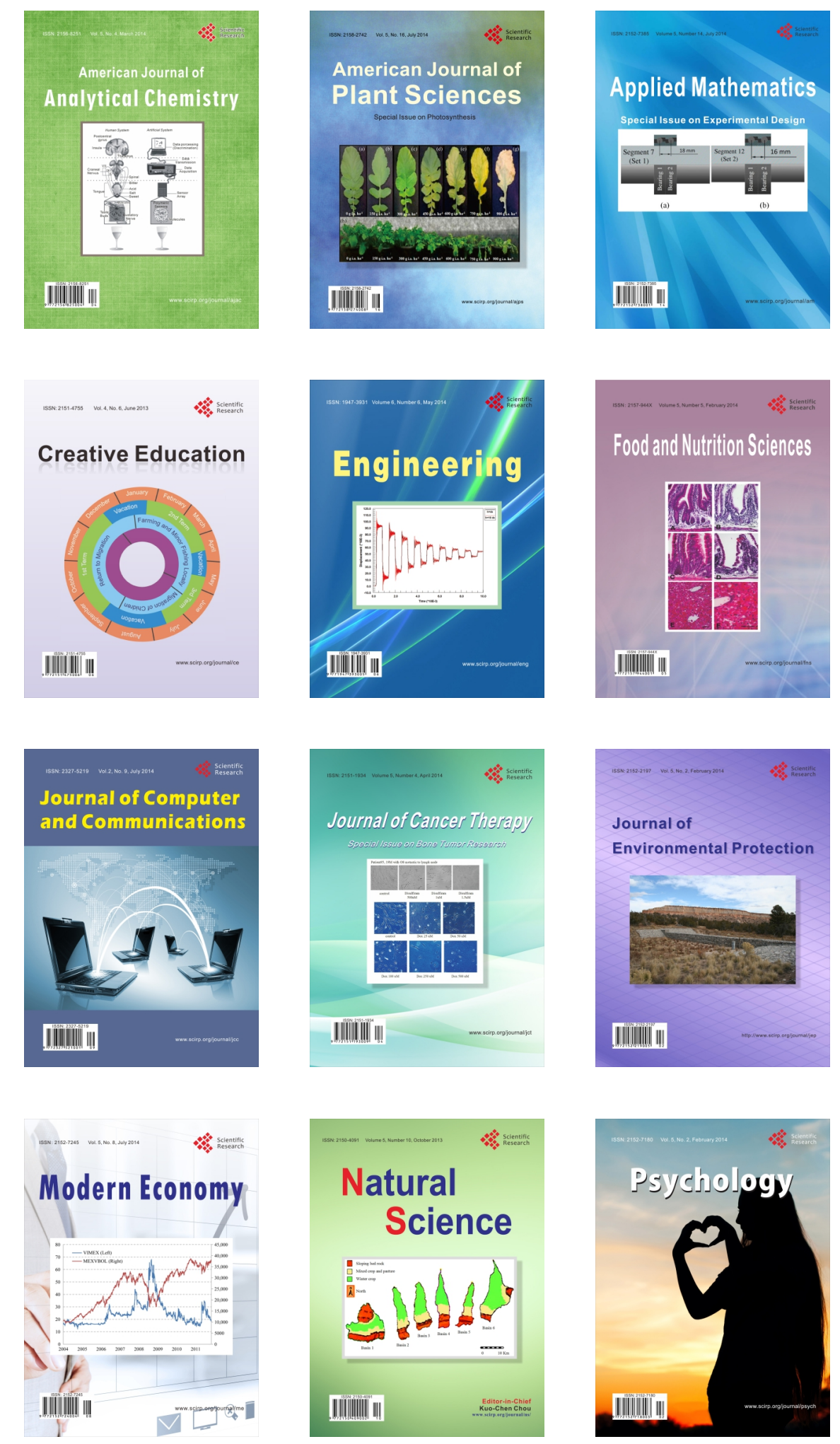